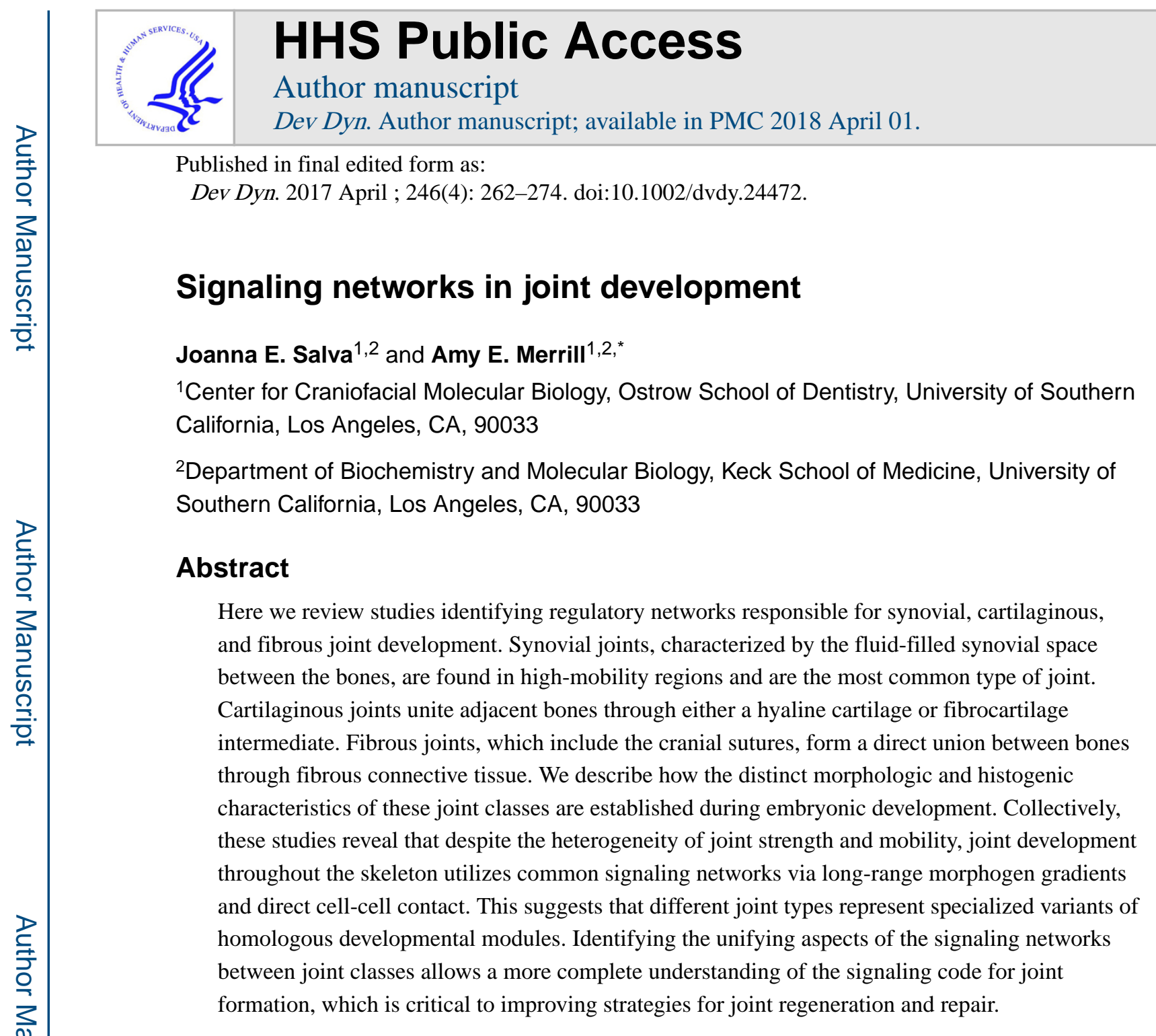

Keywords

synovial joint; cartilaginous joint; fibrous joint; IVD; suture; FGF; hedgehog; Wnt; Bmp

\title{
Introduction
}

Joints connect articulating elements of the vertebrate skeleton. While all joints share this role, their morphologic diversity produces a broad range of mechanical possibilities. The degree of strength and mobility is controlled by the composition of joint connective tissues, whereas the type and range of motion is conferred by joint shape. There are three major classes of joints: freely movable synovial joints, slightly movable cartilaginous joints, and immovable fibrous joints. The distinct morphologic and histogenic characteristics of each joint class are established during embryonic development. Despite this heterogeneity, joint development collectively utilizes common signaling mechanisms via long-range morphogen gradients and direct cell-cell contact. These signaling processes are critical to establish and maintain a transcriptional profile unique to the joint-forming compartment.

‘Correspondence: amerrill@usc.edu. 
Here we review studies that have identified the principal signaling pathways within the regulatory networks for synovial, cartilaginous, and fibrous joint development. In doing so, we reveal that these signaling pathways, as well as their hierarchical relationships, are reiteratively used across joint types. We discuss overlapping signaling architecture between distinct joint classes and discuss evidence that different joint types are homologous developmental modules that have undergone specialization. By identifying the unifying aspects of the signaling networks between joint classes, we hope to gain a more complete understanding of the signaling code for joint formation, which is a critical first step in unlocking the potential for joint regeneration and repair.

\section{Signaling networks in joint development}

\section{Synovial joints}

1.1 Synovial joint structure-Synovial joints, found in high-mobility regions such as the limbs and their girdles, are the most common and structurally variable of all the joint types. A distinguishing characteristic of a synovial joint is the fluid-filled cavity that separates the articulating surfaces of the bones. The jointed bones, which come in a variety of configurations, are composed of hyaline cartilage, a permanent avascular tissue that reduces joint friction through its secretion of hyaluronate and lubricin (Ray et al., 2015). The joint cavity is enclosed by the stratified structure of the joint capsule. Lining the inner surface is a thin synovial membrane that secretes synovial fluid to lubricate the joint. The capsule's outer layer of dense fibrous connective tissue is fastened into the boney epiphyses to structurally support the articulation. In most joints, the fibrous layer is locally thickened into the capsular ligament, which in some cases may be replaced by tendon. Frequently, the capsular tissue invades the synovial joint cavity, dividing it completely or incompletely, as a fibrocartilage articular disc or meniscus, respectively. Further structural support for the joint capsule is provided by accessory ligaments, which can lie inside or outside the capsule and prevent damage from overextension.

1.2 Signals in synovial joint development-The first morphological sign of synovial joint development is the emergence of the interzone, a dense population of pre-chondrogenic mesenchyme that lies between adjacent cartilaginous anlagen (Pitsillides and Ashhurst, 2008). Early studies demonstrated that removal of the interzone leads to fusion of articulating skeletal elements, indicating its necessity for joint formation (Holder, 1977). The interzone is composed of three layers: two dense outer layers of round cells separated by an inner layer of flattened cells. Light and electron microscopic analyses suggest that the outer layers contribute to the growing long bone epiphyses while the inner layer forms the articular surfaces (Ito and Kida, 2000). Taken together, the evidence indicates that the interzone cells are a population of joint progenitor cells critical for forming multiple tissues of the mature joint.

1.2.1 Bmp: Gdf5, a member of the BMP family of secreted factors, is one of the earliest known markers for the presumptive interzone and is an autonomous regulator of synovial joint development. Gdf5 expression is initially limited to the site of the future joint prior to the emergence of the interzone (Storm and Kingsley, 1996; Francis-West et al., 1999a). 
Lineage tracing of Gdf5+ cells demonstrates their contribution to the epiphysis, articular cartilage, joint capsule, and intra-articular ligaments (Rountree et al., 2004; Koyama et al., 2007; Koyama et al., 2008). Mice null for $G d f 5$ exhibit abnormalities in the synovial joints of the limb, with partial or complete fusion of the jointed bones (Storm and Kingsley, 1996; Storm and Kingsley, 1999). While Gdf5 is expressed in nearly all synovial joints of the appendicular skeleton, some joints remain unaffected in the limbs of Gdf5 null mice. This is likely due to functional redundancy with Gdf6 and Gdf7, fellow Bmp family members with joint-specific expression and a high degree of homology to Gdf5 (Wolfman et al., 1997; Settle et al., 2003). Mice null for both $G d f 5$ and $G d f 6$ exhibit more extensive joint fusions not seen in the individual mutants, suggesting functional redundancy of these genes in joint development (Settle et al., 2003).

While Gdf5 is required for synovial joint development, it is not sufficient to induce formation of an ectopic joint. Instead, treatment of developing limbs with recombinant Gdf5-soaked beads promotes cartilage growth (Storm and Kingsley, 1999). Additionally, Gdf5 overexpression in chicks and mice expands the epiphyses, lengthens the bone, and ablates the joint (Francis-West et al., 1999a; Tsumaki et al., 2002). It is interesting that both too much and too little Gdf5 signaling result in joint loss. That the developing synovial joint is exquisitely sensitive to gradients of Bmp signaling is also supported by the dynamic expression patterns of Bmp pathway components. Bmp2 is co-expressed with Gdf5 after the interzone is established (Francis-West et al., 1999b; Seemann et al., 2005). Bmp inhibitors Noggin and Chordin are expressed in the early interzone, with Noggin later being regionally restricted to the epiphysis several layers from the interzone (Francis-West et al., 1999b; Seemann et al., 2005; Ray et al., 2015). Cells between the Chordin-expressing interzone and the Noggin-expressing region of the epiphysis are responsive to the pro-chondrogenic signal from Bmp and form the articular cartilage (Ray et al., 2015). Increasing the zone of Bmp signaling through Noggin inactivation or ectopic activation of Bmp receptors Bmprlb and Acrv1/Alk2 leads to mis-differentiation of the interzone and articular cartilage into growth plate-like cartilage (Zou et al., 1997; Brunet et al., 1998; Agarwal et al., 2015; Ray et al., 2015).

While it is largely accepted that Gdf5 expression marks joint progenitor cells, the source of these progenitor cells has been debated. It was initially thought that all joint progenitor cells were specified in a single early event and originated in the interzone. However, evidence suggests that cells from outside the interzone also contribute to the developing joint. Lineage tracing in avian embryos with DiI shows mesenchymal cells adjacent to the interzone migrating into the developing synovial joint (Pacifici et al., 2005). Genetic lineage tracing in mice shows that Col2a1+ cells within the pre-chondrogenic anlagen give rise to the interzone and subsequently the articular cartilage, ligaments, and medial meniscus. However, Col2a1- cells from outside the anlagen later contribute to the lateral meniscus (Hyde et al., 2008).

During early joint development there is a significant increase in the cellularity of the interzone; however, the Gdf5+ cells in the interzone proliferate at a very slow rate (Ray et al., 2015). Lineage tracing of Col2a1+ cells showed a zone of proliferative cells at the distal ends of the cartilage anlagen contributing to the growth of the interzone and articular 
cartilage. The notion that joint progenitor cells are indeed derived from multiple origins is further substantiated in another recent study. Transient labeling of Gdf5+ cells at distinct time points during joint development identifies a continuous influx of new Gdf5+ cells into the interzone to sustain joint development (Shwartz et al., 2016). The source of the recruited cells is proposed to be a population of Sox9+/Gdf5- cells flanking the developing joint, which is consistent with previous studies showing that all joint structures are derived from Sox9+ cells (Soeda et al., 2010). Timing of Gdf5+ cell recruitment influences the tissue type to which the cells contribute (Shwartz et al., 2016). That there is a continuous influx of Gdf5+ cells into the developing joint seems to conflict with earlier studies showing that the interzone is necessary for joint development (Holder, 1977). However, this could be explained by an instructive role for the interzone in new Gdf5+ cell recruitment.

1.2.2 Wnt: Wnt signaling is also an early regulator of synovial joint formation and maintenance. Wnt4, Wnt9a (previously known as Wnt14) and Wnt16 are expressed in overlapping and complementary patterns in and around the presumptive joint. While all are expressed in the joint interzone, Wnt4 expression is higher in the mesenchyme flanking the joints that gives rise to the joint capsule, and Wnt9a is enriched in the mesenchyme surrounding the cartilage primordium in the tissue that will become tendon (Hartmann and Tabin, 2001; Guo et al., 2004). Wnt16, on the other hand, is joint-specific with high expression levels restricted to the joints of the digits (Guo et al., 2004). Mis-expression of Wnt9a in chicks produces gaps in the cartilage matrix that have the morphological and molecular hallmarks of an interzone (Hartmann and Tabin, 2001). That Wnt signaling is sufficient for joint specification has also been shown in mice expressing Wnt9a or a constitutively active form of the canonical Wnt effector $\beta$-catenin in Col $2+$ cells (Guo et al., 2004).

However, knockout studies demonstrate that Wnt signaling is not necessary for joint induction but rather for maintenance. Wnt 9 a knockout mice initiate joint formation; however, shortly after specification, the interzone cells ectopically differentiate into cartilage, subsequently causing joint fusions (Spater et al., 2006a; Spater et al., 2006b). Mice null for Wnt9a and Wnt4 have a more severe phenotype with ectopic cartilage and fusion in additional joints (Spater et al., 2006a; Spater et al., 2006b). Furthermore, in $\beta$-catenin knockout mice the joint interzone initially forms but later fails to maintain joint identity and undergoes chondrogenesis (Guo et al., 2004; Spater et al., 2006b). These studies suggest that canonical Wnt signaling blocks chondrogenesis in the interzone during joint development. While Wnt exhibits anti-chondrogenic activity in the interzone, it supports formation of the articular cartilage. A recent study shows that Wnt and Bmp signaling oppose one another to control the zone of chondrogenic activity. Noggin expression in the epiphysis blocks Bmp signaling in a region of interzone-adjacent cells, allowing their differentiation into articular cartilage under the influence of Wnt from the interzone (Ray et al., 2015). Thus, Bmp signaling activates programs for transient cartilage of the growth plate, whereas Wnt signaling promotes programs for articular cartilage.

While Wnt9a is critical for joint development, it is only necessary after joint specification, suggesting the presence of an upstream regulator. In a study aimed to identify direct transcriptional activators of Wnt9a in the developing joint, c-Jun was identified as a critical 
regulator of cell fate in the interzone (Kan and Tabin, 2013). Conditional deletion of c-Jun decreases canonical Wnt signaling, prevents formation of the characteristic flat interzone cells, and leads to a range of abnormalities from ectopic cartilage between the articular surfaces to irregular articular surfaces and ligament hypoplasia. The chondrogenic switch in the cell fate of the interzone cells can be explained by enhanced Bmp signaling due to downregulation of Chordin.

1.2.3 Hedgehog: There is strong evidence to suggest that the developing bones influence the establishment and maintenance of the interzone as signaling center. Signals from the adjacent cartilage anlagen that regulate growth and maturation of chondrocytes within the growth plate also influence joint formation. Indian hedgehog (Ihh), expressed by prehypertrophic chondrocytes in the growth plate, controls the distance between the hypertrophic zone and the articular surface of the joint through a negative feedback loop with Pthrp. Ihh indirectly promotes Pthrp expression in the periarticular joint region and in turn, the range of Pthrp signaling determines the length of the proliferative zone (Lanske et al., 1996; Vortkamp et al., 1996; Karp et al., 2000). Mice lacking Ihh exhibit long bone defects, as well as joint fusions (St-Jacques et al., 1999; Koyama et al., 2007; Decker et al., 2014). While Gdf5+ joint progenitors are specified in these mice, the cells mislocalize to the perichondrium at the periphery of the future joint (Koyama et al., 2007; Decker et al., 2014). This suggests that Ihh is critical for the influx of joint progenitors flanking the prospective joint.

Although Pthrp and Ihh work together in the growth plate, this regulatory relationship is not entirely conserved in joint development. Constitutively active Pth1r is not sufficient to rescue joint fusions in Ihh knockout mice (Amano et al., 2016). In fact, the developing joint can respond directly to hedgehog by expressing pathway effectors such as Gli1, Gli3, Hip1, and Patched1 (Mak et al., 2006; Koyama et al., 2007). Activation of Ihh signaling in Col2expressing cells directly stimulates mis-differentiation of the periarticular cells into columnar chondrocytes by increasing Bmp expression (Kobayashi et al., 2005; Mak et al., 2006). Correspondingly, joint fusions in these mice are rescued by treatment with Noggin (Mak et al., 2006). Furthermore, increased Ihh signaling in the joint interzone induced by loss of Patched1 or expression of SmoM2 blocks formation of articular cartilage and menisci and induces ectopic cartilage formation by inhibiting Wnt/ $\beta$-catenin target genes such as Fgf18 (Rockel et al., 2016). Fgf18 treatment blocks ectopic cartilage formation induced by hedgehog activation in these mice. Together these results show that opposing Wnt/ $\beta$-cateninFgf and Ihh-Bmp signals regulate cell fate in the interzone.

1.2.4 Mechanotransduction: During joint cavitation, the articulating cartilage surfaces of the jointed skeletal elements become separated by a fluid-filled space. Early studies proposed that the cavity between the bones was generated through apoptosis of the cells located in the center of the interzone (Mitrovic, 1977). However, cell death is quite restricted and thus unlikely to be the driving force in cavitation (Ito and Kida, 2000; Kavanagh et al., 2002). An alternative view is that separation relies on mechanically induced changes in the extracellular matrix (ECM), particularly the production of hyaluronan, which contributes to the loss of cell-cell integrity at the plane of cleavage (Dowthwaite et al., 1998; Lamb et al., 
2003). Since synovial joints are specifically adapted for motion, it is not surprising that their formation requires input from extrinsic mechanical forces. Indeed, skeletal muscle paralysis prevents joint cavitation despite normal formation of the interzone; moreover, mechanical stimulation from the skeletal muscle is necessary for maintenance of already cavitated joints (Drachman and Sokoloff, 1966; Murray and Drachman, 1969; Mitrovic, 1982; Osborne et al., 2002).

Less is known about how mechanical cues are translated into cellular signals during embryogenesis to mediate a transcriptional response in the interzone cells. Candidate pathways for mechanotransduction in the joint have been suggested by the identification of genes with mechanoresponsive expression. Mechanical stimuli activate two key effectors downstream of Fgf2 signaling, mitogen-activated protein kinases P38 and Erk1/2, in the presumptive joint line and promote production of hyaluronan-rich matrices (Bastow et al., 2005; Lewthwaite et al., 2006). On the other hand, immobilization of avian embryos diminishes expression of Fgf2 in the presumptive joint line prior to cartilaginous fusion (Kavanagh et al., 2006). More localized joint immobilization in mice leads to a decrease in Fgf2 at the articular surface, loss of Bmp2 within the interzone, and expansion of Pthrp expression in the periarticular cartilage into the joint line region (Roddy et al., 2011). A recent genome-wide survey to identify mechanosensitive genes differentially expressed in the limb skeleton of the $P a \times 3^{S p d}$ muscle-less mouse model uncovered changes in membraneassociated proteins including members of the Wnt, Fgf, Notch, and Eph/ephrin pathways (Rolfe et al., 2014).

Mechanical loading is critical to maintain the joint's articular surface and thus, more is known about the role of mechanotransduction in joint maintenance. TRPV4, a mechanosensitive ion channel in articular chondrocytes, induces cartilage-specific gene expression and matrix biosynthesis through an intracellular influx of $\mathrm{Ca}^{+2}$ following normal mechanical loading (Lamande et al., 2011; O'Conor et al., 2014). Reduced TRPV4 activity leads to irregularities in the articular surface and subsequently deforming osteoarthritis (Lamande et al., 2011). $\mathrm{Ca}^{+2}$-induced signaling induced by normal joint motion is critical for CREBdependent activation of Prg4, the gene encoding the secreted proteoglycan lubricin, in articular chondrocytes (Ogawa et al., 2014). However, not all mechanically induced signals in the joint are beneficial. Ion channels PIEZO1 and 2 in articular chondrocytes potentiate $\mathrm{Ca}^{+2}$ signals in response to pathological joint loading that induce cell death (Lee et al., 2014). Attenuation of PIEZO1 and 2 is chondroprotective following injurious mechanical strain. Thus, articular chondrocytes sense and respond to variations in mechanical load via $\mathrm{Ca}^{+2}$-induced signaling.

1.3 Future directions-Despite advancements in our understanding of interzone specification, maintenance, and eventual cavitation, many questions still remain. While a variety of signals that regulate synovial joint development have been identified (Figure 1A), the signal or combination of signals that are both necessary and sufficient for specification of joint progenitor cells is unknown. Wnt signaling is the only pathway shown to be sufficient for joint establishment, and yet it appears not to be necessary. One possibility is that there is more Wnt pathway redundancy during specification than has been explored with the $\beta$-catenin knockout or Wnt9a; Wnt4 double knockout mouse lines. After the interzone is 
specified, Bmp, Wnt, Ihh, and Pthrp signaling coordinate histogenesis of the joint. It is unclear how the combinatorial effects of these pathways on synovial joint progenitor cells lead to the multiple cell types within the mature joint. Certainly, signaling mechanisms that facilitate cell-cell communication and cellular boundaries to coordinate cell fate decisions are likely at play, but little is known about the role of such regulators including Eph/ephrin and Notch. These very same pathways are also candidate regulators for the process of cavitation. As cavitation advances, the articular surfaces of the opposing bones undergo the process of morphogenesis, in which their three-dimensional structure takes shape. Synovial joints are the most structurally diverse of all joint types, including ball-and-socket joints in the hip and shoulder, saddle joints in the digits, hinge joints in the elbows and knees, and gliding joints in the wrist. The signaling mechanisms that produce this variation and also coordinate the shapes of the interlocking articular ends are largely unknown. Synovial joints show variable expression of and different sensitivity to signaling pathway components according to their anatomical location. It will be important to explore correlations between expression differences, signaling intensity and duration, and joint patterning.

\section{Cartilaginous joints}

2.1 Cartilaginous joint structure-Cartilaginous joints unite adjacent bones through either a hyaline cartilage or fibrocartilage intermediate. There are two types of cartilaginous joints, synchondroses and symphyses. Synchondroses are immovable and usually temporary joints made of hyaline cartilage that allow interstitial growth between ossification centers before their eventual fusion. Temporary synchondroses are located between the primary ossification centers of the growing cranial base and the developing hip, as well as within the growth plates of the long bones. Permanent synchondroses that remain unossified are located in the thoracic cage between the ribs and the sternum. Symphyses, on the other hand, are joints that allow for limited movement and are composed of fibrocartilage. A symphysis can span a narrow or wide joint space, as in the narrow strip of fibrocartilage that fills the pubic symphysis, or the thick pad of fibrocartilage that fills the space between adjacent vertebrae.

Here we will discuss the signaling mechanisms involved in the most studied example of a cartilaginous joint apart from the growth plate: the intervertebral symphysis, commonly known as the intervertebral disc (IVD). Along the spinal column, adjacent vertebrae are linked together by IVD, which provide mechanical stabilization, flexibility, and the ability to bear a significant load. In the mature IVD, concentric connective tissue rings of the annulus fibrosus (AF) enclose a gel-like center known as the nucleus pulposus (NP). The outer layer of the AF is tendon-like in its morphology, while the inner layer resembles hyaline cartilage (Postacchini et al., 1984). The AF anchors the IVD between two articulating vertebral bodies through the hyaline cartilage endplates. Specifically, the outer AF is anchored to the vertebral body and endplate while the inner AF inserts directly into the endplate (Nosikova et al., 2012).

2.2 Signals in IVD development-The AF, along with the vertebral bodies and their endplates, is embryonically derived from the sclerotome (Mundy et al., 2011; Bruggeman et al., 2012). While the sclerotome arises from cells within the ventral medial somites and somitocoele, it is the sclerotome cells of somitocoele lineage that give rise to the AF (Huang 
et al., 1994; Mittapalli et al., 2005). Interestingly, the somitocoele is known as the jointforming compartment of the somites. The NP component of the IVD, on the other hand, is derived from the notochord (Choi et al., 2008; McCann et al., 2012). Perturbations to the processes leading up to the formation of the sclerotome and/or notochord can therefore result in hypoplastic or dysmorphic IVD. Since the relationship between these early processes and IVD development have been recently reviewed, we will focus on signaling events after specification of the sclerotome and notochord (Sivakamasundari and Lufkin, 2012; McCann and Seguin, 2016).

Following specification, the ventral sclerotome cells expressing Pax 1 and Pax9 migrate and condense around the notochord to form a continuous perichordal tube (Peters et al., 1999; Christ et al., 2000). The perichordal tube acquires a metameric pattern of high and low condensed regions that correspond to the AF and vertebral body, respectively. Pax1, which inhibits chondrogenesis, remains up-regulated in the AF anlagen and is down-regulated in the presumptive vertebral bodies through signals that are yet unknown (Wallin et al., 1994; Peters et al., 1999; Takimoto et al., 2013). However, it is clear that migration and segmentation of the perichordal tube is dependent on signals that emanate from the adjacent notochord. That the notochord regulates development of the perichordal tube was first shown by notochord excision experiments, which resulted in the perichordal tube forming an unsegmented cartilage rod (Strudel, 1955). Later it was shown that Sonic Hedgehog (Shh) derived from the notochord is required for multiple steps in IVD development including maintenance of Pax1 expression in the ventral sclerotome, formation of the perichordal tube, and eventual patterning of the IVDs (Fan and Tessier-Lavigne, 1994; Choi et al., 2012).

As the presumptive vertebral bodies undergo chondrogenesis, the notochord regresses in the vertebral regions and expands in the center of the IVD to form the NP. This regression is a result of notochord cell migration towards the presumptive IVD in response to mechanical cues and/or growth factor gradients originating from the segmenting perichordal tube (Aszodi et al., 1998; Choi and Harfe, 2011; Corallo et al., 2013). That signals from the perichordal tube are critical for NP development is supported by studies showing that changes in perichordal structure or ECM composition disrupt NP formation. In the absence of hedgehog signaling, the perichordal tube does not form and notochord cells disperse throughout the vertebral column instead of coalescing in the presumptive NP (Choi and Harfe, 2011). Furthermore, loss of Pax 1 in cells of the ventral sclerotome leads to abnormalities in the metameric arrangement of the perichordal tube as well as deficiencies in notochord regression and NP formation (Wallin et al., 1994; Zhang and Gridley, 1998).

2.2.1 Notch: Only a few candidate factors are known to mediate the reciprocal interactions between the notochord and perichordal tube during vertebral morphogenesis. Deciphering the precise functions of factors identified thus far has been complicated by their initial roles in somitogenesis and sclerotome determination. The Notch pathway, which first regulates periodicity of somite formation and somite patterning, also regulates the patterning of the perichordal tube. Mice null for Lunatic fringe, a glycosyltransferase that enhances Notch activation though the Delta1 ligand, fail to form the metameric pattern of high and low density mesenchymal condensations around the notochord (Zhang and Gridley, 1998). While Notch signaling through Deltal in the caudal region of the somites is critical for rostral- 
caudal polarity, overexpression of Delta1 throughout the somites does not affect somite polarity but instead results in vertebral column defects including loss of the IVD and incomplete extrusion of the notochord (Takahashi et al., 2000; Teppner et al., 2007). This suggests that negative feedback mechanisms that regulate somite polarity do not function later during IVD morphogenesis.

2.2.2 Hedgehog: Hedgehog signaling is another pathway redeployed throughout axial skeletal development. During somite development, Sonic hedgehog (Shh) from the notochord is required for pacing the somitogenesis clock, inducing formation and survival of the sclerotome, as well as stimulating the sclerotome to be competent for subsequent differentiation into chondrocytes (Fan and Tessier-Lavigne, 1994; Chiang et al., 1996; Teillet et al., 1998; Murtaugh et al., 1999; Resende et al., 2010). Consistent with their origins in the notochord, NP cells continue to express Shh through the early postnatal period to activate growth and differentiation of the NP, AF, and endplate (Dahia et al., 2012). Another hedgehog ligand, Indian hedgehog (Ihh) is released by the hypertrophic zone of the vertebral body growth plate and influences cartilage maturation in the IVD. In mice with postnatal conditional deletion of Ihh in Col2-expressing cells, the IVD lose the AF and hyaline cartilage endplate (Maeda et al., 2007). As seen in synovial joints, Ihh is critical for maintaining distinct regions of cartilage maturation at the articulating surface of the IVD.

2.2.3 Wnt: The effect of Shh on growth and differentiation of the NP relies on Wnt signaling. Conditional knockout of Wntless, which is necessary for Wnt secretion, in Shhexpressing cells results in downregulation of Shh target genes (Winkler et al., 2014). Since canonical Wnt signaling is up-regulated in the NP upon loss of Shh, a negative feedback loop has been suggested: Wnt signaling activates Shh signaling, which in turn represses Wnt signaling. The effects of Wnt signaling on IVD development are more extensive as its activity and localization dynamically change in the IVD between embryonic and postnatal stages (Kondo et al., 2011). Outside the NP, Wnt signaling is a known inhibitor of chondrogenesis and is active in the end plate and AF. Conditional deletion of $\beta$-catenin in Col2-expressing cells leads to increased endochondral bone formation in the endplate (Kondo et al., 2011). Furthermore, transient over-activation of Wnt signaling in the postnatal IVD caused deterioration of the AF (Kondo et al., 2011). This suggests that Wnt signaling regulates cell-fate determination and maintenance of the AF.

2.2.4 Bmp and Tgf $\beta$ : In addition to Wnt, Gdf is also involved in AF cell-fate determination and maintenance. Some Gdf5+ cells, which give rise to the AF, were found to reside adjacent to the cartilage endplates and migrate along the lamellae into the disc (Henriksson et al., 2012; Barreto Henriksson et al., 2013). Loss of Gdf5 leads to histogenic abnormalities in the AF including replacement of the normal lamellar architecture with chondroid tissue that invades the NP (Li et al., 2004). Although primary formation of the NP is normal in the absence of Gdf5, the AF abnormalities secondarily result in NP deformity and degeneration (Maier and Harfe, 2011). Similarly, increased BMP signaling leads to changes in AF histogenesis. A Noggin-expressing layer in the IVD blocks pro-chondrogenic Bmp signals from the adjacent vertebral bodies (DiPaola et al., 2005) and loss of Noggin leads to bone 
formation in the region of the AF and vertebral fusions (Brunet et al., 1998; DiPaola et al., 2005).

AF histogenesis is also regulated by Tgf $\beta$ receptors, which are among the earliest known markers of the presumptive IVD (Pelton et al., 1990; Matsunaga et al., 2003). Conditional inactivation of $\operatorname{Tgf} \beta$ type II receptor ( $T g f \beta r 2)$ in Col2-expressing cells of the AF leads to inappropriate chondrogenesis, fusion of the $\mathrm{AF}$ and vertebral body, and subsequently, loss of the IVD (Baffi et al., 2004). The anti-chondrogenic role of Tgf $\beta \mathrm{r} 2$ is in part mediated through the induction of AF specific transcription factors such as Scx, fibromodulin, Erg1, and Mohawk in the sclerotome (Sohn et al., 2010; Cox et al., 2014). Correspondingly, loss of Mohawk, which promotes responsiveness to Tgf $\beta$ and reduces responsiveness to Bmp in the outer AF layer, leads to down-regulation of tendon/ligament markers and up regulation of the chondrogenic factor Sox9 (Nakamichi et al., 2016). That the balance between TGF $\beta$ and BMP signaling is critical for AF maintenance is supported by loss of Filamin B, a scaffold protein that regulates signaling attenuation of the $\operatorname{Tgf} \beta$ family of receptors. In Filamin B knockout mice, which exhibit enhanced Tgf $\beta$ and Bmp signaling, AF cells acquire the molecular signature of hypertrophic chondrocytes undergoing endochondral-like ossification (Zieba et al., 2016). The latent ability of cells in the outer layer of the AF to differentiate into chondrocytes can be explained by the finding that the AF is derived from Scx+/Sox9+ bipotent progenitor cells that differentiate into either chondrocytes or tenocytes (Sugimoto et al., 2013). Correspondingly, conditional deletion of Sox9 in Scx+/Sox9+ cells causes hypoplasia of the inner AF and expansion of the outer AF layer (Sugimoto et al., 2013).

2.3 Future directions-What is known and reviewed here is likely only part of a larger signaling network controlling IVD development and maintenance (Figure 1B). Expression analyses have identified multiple components of the Wnt, Hedgehog, Fgf, Bmp, and Tgf $\beta$ signaling pathways in the IVD (DiPaola et al., 2005; Dahia et al., 2009). However, functional studies have yet to reveal the full extent to which these pathways regulate IVD formation and maintenance. Mechanical loading is a key regulator of IVD homeostasis and yet the molecular signals that sense and convert mechanical stimulus into a cellular response during IVD development are unknown (Kerr et al., 2016). Mechanotransduction pathways, while incompletely defined in the IVD, are likely to overlap with those of the synovial joint. Basic knowledge of the signaling pathways regulating the IVD, as well as a better understanding of their hierarchy and interconnectedness, will be critical to identifying therapeutic targets in IVD degeneration, for which there are few effective treatments.

\section{Fibrous joints}

3.1 Fibrous joint structure-Fibrous joints form a direct union between bones through fibrous connective tissue. There are three types of fibrous joints: syndesmoses, gomphoses, and sutures. Syndesmoses traverse widely spaced parallel bones through bands of ligaments or sheets of connective tissue called interosseous membranes. These joints provide strength, stability, and limited movement between the shafts of the radius and ulna in the forearm and the tibia and fibula of the leg. Gomphoses are specialized fibrous joints that anchor the roots of teeth to the bony sockets in the upper and lower jaw via a thin fibrous membrane called 
the periodontal ligament. Sutures bind the contiguous margins of closely opposed bones in the skull through short connective tissue fibers that restrict most movement and yet provide compliance and elasticity during parturition and postnatal brain growth. By adulthood in humans, many sutures ossify to permanently fuse adjacent bones. The signaling mechanisms that regulate suture development are the best described of all fibrous joints and therefore will be the example we discuss here.

3.2 Signals in suture development-A suture is established when the osteogenic fronts of opposing calvarial bones meet following their apical growth. Once formed, the osteogenic fronts and intervening mid-suture mesenchyme organize subsequent calvarial bone growth by coordinating intramembranous ossification in response to mechanical forces from the enlarging brain until the eventual fusion of the sutures in late adolescence. Intramembranous ossification is spatially organized within the sutures. Preosteoblasts located within the osteogenic front terminally differentiate and withdraw from the growing front to incorporate into the bone. Proliferating osteoprogenitor cells, on the other hand, are maintained at the tip of the osteogenic fronts and advance with the developing bone (Lana-Elola et al., 2007). The mid-suture mesenchyme maintains a non-osteogenic fate during the embryonic period, and as the suture matures, the mid-suture zone becomes occupied by fibrous connective tissue (Markens, 1975).

Calvarial bones and their intervening sutures are embryonically derived from neural crest and paraxial mesoderm. Frontal bones in the rostral calvaria arise from neural crest mesenchyme, while occipital and parietal bones of the caudal calvaria develop from mesoderm (Couly et al., 1993; Jiang et al., 2002; Evans and Noden, 2006; Yoshida et al., 2008). Interestingly, the coronal suture, situated between the frontal and parietal bones, coincides with a physical boundary between neural crest and mesoderm in mammals (Jiang et al., 2002; Yoshida et al., 2008). While neural crest cells and mesoderm each contribute an osteogenic front to the coronal suture, the mid-suture mesenchyme here is of mesodermal origin. The coronal mid-suture mesenchyme is pre-specified as a population of Gli1+ cells within the head mesoderm prior to the formation of the calvarial bone rudiments (Deckelbaum et al., 2012). These Gli1+ cells, activated by Shh from the notochord and prechordal plate, transiently express En1 and migrate first to the supraorbital ridge and then apically to their position at the neural crest-mesoderm boundary. Lineage tracing of a similar population of Gli+ cells in the adult suture shows they can contribute to the osteogenic front, dura, periosteum, and calvarial bones (Zhao et al., 2015).

3.2.1 Eph/Ephrin: Suture development depends on the establishment and maintenance of cellular boundaries between osteogenic and non-osteogenic territories via direct cell-cell signaling mechanisms. Loss of boundary integrity between osteogenic and non-osteogenic compartments induces ectopic ossification of the mid-suture mesenchyme and subsequently, joint fusion. Normally, as the calvarial bones grow, osteogenic precursor cells from the bone rudiments migrate apically along the developing bone, guided by EphA/ephrinA signaling, to join the leading edge of the bones (Yoshida et al., 2008; Ting et al., 2009; Roybal et al., 2010). EphrinA-expressing osteogenic precursors migrate along an EphA-expressing cell layer located on the apical surface of the bone. Activation of the EphA by ephrinA initiates 
bidirectional signaling that promotes cell-cell repulsion. When expression levels of EphA or ephrinA are reduced, unrestrained osteogenic cells migrate off their path into the nonosteogenic compartment of the mid-suture mesenchyme and cause suture fusion (Merrill et al., 2006; Ting et al., 2009).

3.2.2 Notch: Notch/Jagged signaling is also critical for delineating boundaries between osteogenic and non-osteogenic compartments. Active Notch2 signaling is restricted to the osteogenic fronts of the coronal suture by a layer of Jagged1-expressing cells in the midsuture mesenchyme (Yen et al., 2010). Upon conditional loss of Jagged1 in the mesoderm, but not the neural crest, Notch2 signaling expands into the mid-suture mesenchyme, triggering misspecification to an osteogenic fate, and ultimately leading to joint fusion (Yen et al., 2010). While the roles of Notch/Jagged and EphA/ephrinA signaling in suture boundaries are not directly linked, both pathways lie downstream of Twist1, a transcriptional regulator critical for suture morphogenesis (Merrill et al., 2006; Yen et al., 2010).

3.2.3 Fgf: Fgf signaling is a critical regulator of suture development and maintenance. Osteoprogenitor cells at the osteogenic front express Fgfr2, which is down-regulated upon differentiation. The onset of osteoblast differentiation in the osteogenic front is concomitant with a transient increase in Fgfr1 expression that is later reduced in the mature osteoblasts of the bone (Iseki et al., 1997; Kim et al., 1998; Iseki et al., 1999). Human mutations that increase the activity of FGFR1 or FGFR2 are a major cause of premature suture fusion, known as craniosynostosis (Twigg and Wilkie, 2015). Similarly, mice carrying orthologous mutations in Fgfr 1 and Fgfr2 develop craniosynostosis before birth due to enhanced osteoprogenitor cell proliferation and differentiation (Zhou et al., 2000; Eswarakumar et al., 2004; Wang et al., 2005; Yin et al., 2008; Wang et al., 2010; Pfaff et al., 2016).

Fgfr2 functions cell-autonomously within the sutures. Conditional expression of a diseasecausing Fgfr2 mutation in En1-expressing coronal suture progenitor cells is sufficient to induce craniosynostosis (Deckelbaum et al., 2012; Holmes and Basilico, 2012). Interestingly, loss of Fgfr 2 simultaneously leads to craniosynostosis of the coronal suture and open gaps where frontal and sagittal sutures should form (Eswarakumar et al., 2002; Yu et al., 2003). This apparent paradox is later reconciled through growth. The osteogenic fronts of paired frontal and paired parietal bones are slow to approximate, due to decreased osteoprogenitor cell proliferation and differentiation, and eventually fuse during postnatal development (Eswarakumar et al., 2002; Pfaff et al., 2016).

A precise spatial gradient of Fgf signaling is critical to establish and maintain the sutures. Multiple Fgfs are expressed in and around the sutures. $F g f 2$ and $F g f 9$ are expressed in the mid-suture mesenchyme, while $F g f 18$ is expressed in the osteogenic mesenchyme of the bone (Kim et al., 1998; Rice et al., 2000; Ohbayashi et al., 2002). These Fgfs act on Fgfr1and Fgfr2-expressing cells in the osteogenic fronts and Fgfr3 in the bone. Thus, Fgf signaling is thought to be highest in the osteogenic fronts (Iseki et al., 1997; Iseki et al., 1999). Fgf18 knockout mice exhibit suture widening, while no phenotypes have been identified in $F g f 2$ and $F g f g$ knockout mice (Liu et al., 2002; Ohbayashi et al., 2002). Ectopic treatment of the developing sutures with Fgf2-soaked beads show that Fgf2 can promote mid-suture cell identity by inducing Twist 1 , a negative regulator of osteogenesis that directly 
inhibits Runx2 (Rice et al., 2000; Bialek et al., 2004). The spontaneous mouse mutant Elbow knee synostosis (Eks) harbors a point mutation in Fgfg that increases ligand diffusion. More diffusible Fgf9 activates Fgfr3 in the bone, a region that normally receives low levels of Fgf, leading to fusion of the coronal and sagittal sutures (Murakami et al., 2002; Harada et al., 2009). That spatial localization of the Fgf gradient determines the cellular response is further supported by the finding that Fgf4 bead placement at the osteogenic fronts accelerates proliferation and differentiation, whereas placement on the mid-suture mesenchyme strictly enhances proliferation (Kim et al., 1998). Additionally, the spatial responsiveness of receptors to the Fgf gradient is critical for suture development: inappropriate localization of Fgfr 1 or changes in ligand-binding specificity of Fgfr 2 cause coronal suture fusion (Hajihosseini et al., 2001; Yu and Ornitz, 2001).

3.2.4 Bmp: Fgf signaling in the suture is tightly linked with Bmp signaling. Bmp4 in the osteogenic fronts and mid-suture mesenchyme is necessary to induce transcription of $M s X 1$ and $M s \times 2$, which are critical regulators of osteoprogenitor cell proliferation and differentiation (Kim et al., 1998; Ishii et al., 2003). Noggin, a secreted antagonist of Bmp expressed in the suture mesenchyme and the underlying dura, restricts Bmp activity to the osteogenic fronts of patent sutures (Warren et al., 2003). While Bmp induces Noggin expression, Fgf signaling inhibits it. The fact that craniosynostosis can result from inappropriate Fgf-mediated repression of Noggin is supported by experiments showing that ectopic application of Noggin can block suture fusion in a chimeric nude rat model (Shen et al., 2009).

The Bmp family member Gdf6 plays a critical role early in establishing the coronal suture. In the developing skull, Gdf6 is first expressed in a supraorbital domain that coincides with the frontal bone rudiment and shortly thereafter is localized to the mid-suture mesenchyme with Fgfr2 (Settle et al., 2003; Clendenning and Mortlock, 2012). Interestingly, this Gdf6+ population appears to spatially overlap with the Gli1+/En1+ cells identified by Deckelbaum et al. that give rise to the coronal suture. Gdf6 mutant mice do not show morphologic or molecular evidence of suture formation (Settle et al., 2003; Clendenning and Mortlock, 2012). In particular, Fgfr2 expression is lost in the coronal suture of Gdf6-null mice in a pattern quite similar to what is seen in En1-null mice, suggesting that these may be the same group of cells (Settle et al., 2003; Deckelbaum et al., 2012).

3.2.5 Hedgehog: The hedgehog pathway controls both early and late events in suture formation. Early in development, Shh from the notochord induces formation of the Gli1+ cells in the mesoderm that eventually give rise to coronal suture progenitors (Deckelbaum et al., 2012). Functional studies suggest that Ihh in the osteogenic fronts integrates with Bmp and Fgf to regulate later events in suture development. Ihh-null mice have delayed calvarial osteogenesis and wide sutures due to a decrease in Bmp-mediated recruitment of osteoprogenitor cells to the osteogenic fronts (Lenton et al., 2011). Loss of negative regulators in the hedgehog pathway also demonstrates that Ihh promotes osteogenesis in the suture. Excessive Ihh signaling in mice caused by reduced levels of Gli3 and Ptch1 leads to increased proliferation, enhanced osteogenesis, and premature fusion of the lambdoid suture (Rice et al., 2010; Tanimoto et al., 2012; Feng et al., 2013). In the mid-suture mesenchyme 
of Gli3 knockout mice, Twist1 expression is reduced, while BMP signaling and Runx2 expression are expanded (Rice et al., 2010; Tanimoto et al., 2012). Allelic reduction of Runx 2 in the Gli3 mutant background rescues suture fusion (Tanimoto et al., 2012). Interestingly, treatment of the Gli3 mutant with Fgf2 reinstates Twist 1 expression and also rescues suture fusion (Rice et al., 2010). Together these studies suggest that Ihh signaling promotes osteogenesis through Bmp-mediated activation of Runx2 and that this activity is counterbalanced by Fgf2-mediated maintenance of Twist 1 .

3.2.6 Wnt: Acting upstream of Fgf and Bmp signaling, Wnt is critical for maintaining suture patency. Wnt/ $\beta$-catenin promotes the commitment of skeletal progenitor cells into osteoprogenitors, and suppresses their chondrogenic potential (Day et al., 2005; Hill et al., 2005). Axin2, a negative regulator of canonical Wnt signaling that promotes $\beta$-catenin degradation, is expressed in the mid-suture mesenchyme as well as the osteogenic fronts and periosteum of the calvarial bones. Axin 2 knockout mice have fusion of the metopic and coronal sutures due to enhanced osteoprogenitor cell proliferation and differentiation (Yu et al., 2005; Behr et al., 2013). This phenotype is concomitant with increased levels of Fgf18, Fgf4 and Fgfr1 expression, as well as elevated BMP signaling (Yu et al., 2005; Liu et al., 2007). Similarly, mice with constitutive activation of $\beta$-catenin in Axin2-expressing cells also exhibit excessive intramembranous ossification that results from increased Fgf and Bmp signaling (Mirando et al., 2010). Thus, these studies strongly suggest that Wnt signaling promotes the expansion of osteoprogenitor cells and the commitment of these cells into the osteoblast lineage through Fgf and Bmp signaling. Reducing elevated Fgf signaling in Axin2 knockout mice through allele reduction of Fgfr 1 does not rescue suture fusion. Instead, these double mutant mice develop craniosynostosis due to ectopic endochondral ossification (Maruyama et al., 2010). This change in cell fate within the mid-suture mesenchyme is blocked by treatment with the Bmp inhibitor Noggin (Maruyama et al., 2010). Together these findings show that Wnt regulates lineage specification within the suture by balancing levels of Bmp and Fgf signaling.

3.3 Future directions-While the structure of the suture may be less complex then the other joints reviewed here, the signaling regulating its development is no less complicated (Figure 1C). Enhanced or diminished activation of a single signaling pathway, such as Fgf, yields the same phenotype - suture fusion. It should be noted that the underlying pathologies of "suture fusion" in these situations are likely distinct. The term "suture fusion" implies that the suture was established but not maintained. However, a subset of these phenotypes are expected to be the result of defective joint specification, or failure to form a suture altogether. In future studies it will be important to distinguish between lack of suture specification and failed maintenance by looking at the development of En1+ suture progenitor cells.

Although movement is highly restricted at fibrous joints, the suture is designed to withstand and respond to mechanical stimuli from the underlying brain and nearby muscles. The mechanoresponsive nature of the suture is directly tied to its primary function in bone growth (Mao, 2002; Byron et al., 2004; Khonsari et al., 2013). The suture would, therefore, be an ideal model to identify mechanotransduction pathways. 


\section{Unifying features of joint development}

Review of the mechanisms that regulate development of synovial, cartilaginous, and fibrous joints reveals that there are unifying features in signaling architecture between distinct joint classes (Figure 2). First, the joint progenitor cells of different joint types express genes that belong to the same principal signaling pathways. For example, the Gdfs, Wnts, and Bmp inhibitors are all expressed in the presumptive joint compartments of synovial, cartilaginous, and fibrous joints. Second, the regulatory relationships between the principal signaling pathways are reiteratively used during the development of distinct joint types. A signaling axis of Wnt-Fgf from within the joint-forming compartment opposes chondrogenic signals from Ihh-Bmp in order to promote specification and differentiation of specialized tissues at the joint-bone interface. In synovial and cartilaginous joints, the balance between Wnt and Ihh signaling promotes formation of intermediate tissues such as hyaline cartilage and fibrous connective tissue by limiting chondrogenic potential. In the fibrous joint of the suture, Wnt and Ihh signaling maintain the osteogenic front by balancing osteoprogenitor cell specification with terminal osteoblast differentiation. Third, the same signal pathway is utilized for the same function in distinct joint types. Cell-cell signaling through the Notch pathway is employed in the IVD and suture to define osteogenic and non-osteogenic compartments. Similarities in the molecular regulatory network between joint types are coincident with similarities in joint morphogenesis. Joint progenitor cells that make synovial, cartilaginous, and fibrous joints share a common feature: they are sourced from the outside and move into the joint space.

One possibility raised by previous studies is that diverse types of joints have a common evolutionary origin. The structure of some cranial joints is taxonomically variable in lizards (Payne et al., 2011). While the quadrate-pterygoid joint of the jaw is fibrous in gekkotans, it is a mixed phenotype joint - part fibrous and part synovial - in iguanids. Joints within the axial and appendicular skeleton also vary between tetrapods. The costal joint is fibrous in most mammals and synovial in birds (Parker, 1868; Claessens, 2009). Similarly, the knee joint, which is synovial in mammals, is fibrous and lacks a synovial cavity in amphibians such as the salamander and frog (Lee and Gardiner, 2012). Additionally, joints within the amphibian ankle and wrist show a mixed phenotype of fibrous and synovial. These studies suggest that the signaling network responsible for specifying the joint is competent to generate more than one joint class.

\section{Conclusions}

Overlap in the signaling networks that regulate distinct joint types is certainly more extensive than is appreciated here. The role of Fgf signaling in joint development has been largely defined by studies in the sutures. However, craniosynostosis syndromes caused by mutations in FGFR2 are also associated with synovial joint fusions within the limb as well as intervertebral fusions (Hemmer et al., 1987; Anderson et al., 1998). To understand this regulatory connection, it will be important to more closely examine the role of Fgf signaling in synovial and cartilaginous joint development. 
Despite overlapping signaling mechanisms in the development of the synovial, cartilaginous, and fibrous joints, the final structures of these joints are quite specialized, and there is significant morphological variation within each category. How can use of similar signaling networks across joint types produce the unique histogenic structure of each joint? Signaling pathways can produce varied biological responses depending on the intensity and duration of the signal. Differences in the spatiotemporal expression patterns of signaling pathway components or inhibitors can account for the modulations in dose- and time-dependent response. In the joints, this is evidenced by varied involvement of select Wnt, Gdf, and Fgf ligands, as well as Bmp inhibitors.

Conservation of the regulatory network across joint types may suggest that synovial, cartilaginous, and fibrous joints are homologous developmental modules that have undergone specialization. If they are indeed homologous modules, then the specialized transcription factors that define the joint compartment should be shared across joint types. These joint-determining transcription factors should be expressed within the cells of the presumptive joint compartment, required for initial specification of joint identity, and sufficient for joint specification under the correct conditions (Guss et al., 2001). A transcription factor that fits this description has yet to be identified in any of the joint types.

Here we have illustrated the similarities and differences between distinct joint types in an effort to better understand joint development. By comparing the different joint classes, an overlap in the signaling networks becomes clear. Discoveries in one joint type can therefore provide mechanistic insights into the development of the other joint classes. Since all joint classes are commonly affected by disease and injury, there is a clinical need to develop molecular-based strategies to repair and/or rebuild joint tissues. Identifying unifying features in the mechanisms that instruct joint development enhance our potential to reach this goal.

\section{Acknowledgments}

Grant sponsor: NIDCR; Grant number: R01DE025222

Grant sponsor: March of Dimes; Grant number: \#6-FY15-233

This work was supported by the National Institutes of Health [R01DE025222 to A.E.M.] and March of Dimes [\#6FY15-233 to A.E.M.]. We thank Bridget Samuels for her help in editing this manuscript.

\section{References}

Agarwal S, Loder SJ, Brownley C, Eboda O, Peterson JR, Hayano S, Wu B, Zhao B, Kaartinen V, Wong VC, Mishina Y, Levi B. BMP signaling mediated by constitutively active Activin type 1 receptor (ACVR1) results in ectopic bone formation localized to distal extremity joints. Dev Biol. 2015; 400:202-209. [PubMed: 25722188]

Amano K, Densmore M, Fan Y, Lanske B. Ihh and PTH1R signaling in limb mesenchyme is required for proper segmentation and subsequent formation and growth of digit bones. Bone. 2016; 83:256266. [PubMed: 26620087]

Anderson J, Burns HD, Enriquez-Harris P, Wilkie AO, Heath JK. Apert syndrome mutations in fibroblast growth factor receptor 2 exhibit increased affinity for FGF ligand. Hum Mol Genet. 1998; 7:1475-1483. [PubMed: 9700203] 
Aszodi A, Chan D, Hunziker E, Bateman JF, Fassler R. Collagen II is essential for the removal of the notochord and the formation of intervertebral discs. J Cell Biol. 1998; 143:1399-1412. [PubMed: 9832566]

Baffi MO, Slattery E, Sohn P, Moses HL, Chytil A, Serra R. Conditional deletion of the TGF-beta type II receptor in Col2a expressing cells results in defects in the axial skeleton without alterations in chondrocyte differentiation or embryonic development of long bones. Dev Biol. 2004; 276:124142. [PubMed: 15531369]

Barreto Henriksson H, Lindahl A, Skioldebrand E, Junevik K, Tangemo C, Mattsson J, Brisby H. Similar cellular migration patterns from niches in intervertebral disc and in knee-joint regions detected by in situ labeling: an experimental study in the New Zealand white rabbit. Stem Cell Res Ther. 2013; 4:104. [PubMed: 24004687]

Bastow ER, Lamb KJ, Lewthwaite JC, Osborne AC, Kavanagh E, Wheeler-Jones CP, Pitsillides AA. Selective activation of the MEK-ERK pathway is regulated by mechanical stimuli in forming joints and promotes pericellular matrix formation. J Biol Chem. 2005; 280:11749-11758. [PubMed: 15647286]

Behr B, Longaker MT, Quarto N. Absence of endochondral ossification and craniosynostosis in posterior frontal cranial sutures of Axin2(-/-) mice. PLoS One. 2013; 8:e70240. [PubMed: 23936395]

Bialek P, Kern B, Yang X, Schrock M, Sosic D, Hong N, Wu H, Yu K, Ornitz DM, Olson EN, Justice MJ, Karsenty G. A twist code determines the onset of osteoblast differentiation. Dev Cell. 2004; 6:423-435. [PubMed: 15030764]

Bruggeman BJ, Maier JA, Mohiuddin YS, Powers R, Lo Y, Guimaraes-Camboa N, Evans SM, Harfe BD. Avian intervertebral disc arises from rostral sclerotome and lacks a nucleus pulposus: implications for evolution of the vertebrate disc. Dev Dyn. 2012; 241:675-683. [PubMed: 22354863]

Brunet LJ, McMahon JA, McMahon AP, Harland RM. Noggin, cartilage morphogenesis, and joint formation in the mammalian skeleton. Science. 1998; 280:1455-1457. [PubMed: 9603738]

Byron CD, Borke J, Yu J, Pashley D, Wingard CJ, Hamrick M. Effects of increased muscle mass on mouse sagittal suture morphology and mechanics. Anat Rec A Discov Mol Cell Evol Biol. 2004; 279:676-684. [PubMed: 15224409]

Chiang C, Litingtung Y, Lee E, Young KE, Corden JL, Westphal H, Beachy PA. Cyclopia and defective axial patterning in mice lacking Sonic hedgehog gene function. Nature. 1996; 383:407413. [PubMed: 8837770]

Choi KS, Cohn MJ, Harfe BD. Identification of nucleus pulposus precursor cells and notochordal remnants in the mouse: implications for disk degeneration and chordoma formation. Dev Dyn. 2008; 237:3953-3958. [PubMed: 19035356]

Choi KS, Harfe BD. Hedgehog signaling is required for formation of the notochord sheath and patterning of nuclei pulposi within the intervertebral discs. Proc Natl Acad Sci U S A. 2011; 108:9484-9489. [PubMed: 21606373]

Choi KS, Lee C, Harfe BD. Sonic hedgehog in the notochord is sufficient for patterning of the intervertebral discs. Mech Dev. 2012; 129:255-262. [PubMed: 22841806]

Christ B, Huang R, Wilting J. The development of the avian vertebral column. Anat Embryol (Berl). 2000; 202:179-194. [PubMed: 10994991]

Claessens LP. The skeletal kinematics of lung ventilation in three basal bird taxa (emu, tinamou, and guinea fowl). J Exp Zool A Ecol Genet Physiol. 2009; 311:586-599. [PubMed: 18942101]

Clendenning DE, Mortlock DP. The BMP ligand Gdf6 prevents differentiation of coronal suture mesenchyme in early cranial development. PLoS One. 2012; 7:e36789. [PubMed: 22693558]

Corallo D, Schiavinato A, Trapani V, Moro E, Argenton F, Bonaldo P. Emilin3 is required for notochord sheath integrity and interacts with Scube2 to regulate notochord-derived Hedgehog signals. Development. 2013; 140:4594-4601. [PubMed: 24131633]

Couly GF, Coltey PM, Le Douarin NM. The triple origin of skull in higher vertebrates: a study in quail-chick chimeras. Development. 1993; 117:409-429. [PubMed: 8330517]

Cox MK, Appelboom BL, Ban GI, Serra R. Erg cooperates with TGF-beta to control mesenchymal differentiation. Exp Cell Res. 2014; 328:410-418. [PubMed: 25139621] 
Dahia CL, Mahoney E, Wylie C. Shh signaling from the nucleus pulposus is required for the postnatal growth and differentiation of the mouse intervertebral disc. PLoS One. 2012; 7:e35944. [PubMed: 22558278]

Dahia CL, Mahoney EJ, Durrani AA, Wylie C. Intercellular signaling pathways active during intervertebral disc growth, differentiation, and aging. Spine (Phila Pa 1976). 2009; 34:456-462. [PubMed: 19212276]

Day TF, Guo X, Garrett-Beal L, Yang Y. Wnt/beta-catenin signaling in mesenchymal progenitors controls osteoblast and chondrocyte differentiation during vertebrate skeletogenesis. Dev Cell. 2005; 8:739-750. [PubMed: 15866164]

Deckelbaum RA, Holmes G, Zhao Z, Tong C, Basilico C, Loomis CA. Regulation of cranial morphogenesis and cell fate at the neural crest-mesoderm boundary by engrailed 1 . Development. 2012; 139:1346-1358. [PubMed: 22395741]

Decker RS, Koyama E, Pacifici M. Genesis and morphogenesis of limb synovial joints and articular cartilage. Matrix Biol. 2014; 39:5-10. [PubMed: 25172830]

DiPaola CP, Farmer JC, Manova K, Niswander LA. Molecular signaling in intervertebral disk development. J Orthop Res. 2005; 23:1112-1119. [PubMed: 15936916]

Dowthwaite GP, Edwards JC, Pitsillides AA. An essential role for the interaction between hyaluronan and hyaluronan binding proteins during joint development. J Histochem Cytochem. 1998; 46:641651. [PubMed: 9562572]

Drachman DB, Sokoloff L. The role of movement in embryonic joint development. Developmental Biology. 1966; 14:401-420.

Eswarakumar VP, Horowitz MC, Locklin R, Morriss-Kay GM, Lonai P. A gain-of-function mutation of Fgfr2c demonstrates the roles of this receptor variant in osteogenesis. Proc Natl Acad Sci U S A. 2004; 101:12555-12560. [PubMed: 15316116]

Eswarakumar VP, Monsonego-Ornan E, Pines M, Antonopoulou I, Morriss-Kay GM, Lonai P. The IIIc alternative of Fgfr2 is a positive regulator of bone formation. Development. 2002; 129:3783-3793. [PubMed: 12135917]

Evans DJ, Noden DM. Spatial relations between avian craniofacial neural crest and paraxial mesoderm cells. Dev Dyn. 2006; 235:1310-1325. [PubMed: 16395689]

Fan CM, Tessier-Lavigne M. Patterning of mammalian somites by surface ectoderm and notochord: evidence for sclerotome induction by a hedgehog homolog. Cell. 1994; 79:1175-1186. [PubMed: 8001153]

Feng W, Choi I, Clouthier DE, Niswander L, Williams T. The Ptch1(DL) mouse: a new model to study lambdoid craniosynostosis and basal cell nevus syndrome-associated skeletal defects. Genesis. 2013; 51:677-689. [PubMed: 23897749]

Francis-West PH, Abdelfattah A, Chen P, Allen C, Parish J, Ladher R, Allen S, MacPherson S, Luyten FP, Archer CW. Mechanisms of GDF-5 action during skeletal development. Development. 1999a; 126:1305-1315. [PubMed: 10021348]

Francis-West PH, Parish J, Lee K, Archer CW. BMP/GDF-signalling interactions during synovial joint development. Cell Tissue Res. 1999b; 296:111-119. [PubMed: 10199971]

Guo X, Day TF, Jiang X, Garrett-Beal L, Topol L, Yang Y. Wnt/beta-catenin signaling is sufficient and necessary for synovial joint formation. Genes Dev. 2004; 18:2404-2417. [PubMed: 15371327]

Guss KA, Nelson CE, Hudson A, Kraus ME, Carroll SB. Control of a genetic regulatory network by a selector gene. Science. 2001; 292:1164-1167. [PubMed: 11303087]

Hajihosseini MK, Wilson S, De Moerlooze L, Dickson C. A splicing switch and gain-of-function mutation in FgfR2-IIIc hemizygotes causes Apert/Pfeiffer-syndrome-like phenotypes. Proc Natl Acad Sci U S A. 2001; 98:3855-3860. [PubMed: 11274405]

Harada M, Murakami H, Okawa A, Okimoto N, Hiraoka S, Nakahara T, Akasaka R, Shiraishi Y, Futatsugi N, Mizutani-Koseki Y, Kuroiwa A, Shirouzu M, Yokoyama S, Taiji M, Iseki S, Ornitz DM, Koseki H. FGF9 monomer-dimer equilibrium regulates extracellular matrix affinity and tissue diffusion. Nat Genet. 2009; 41:289-298. [PubMed: 19219044]

Hartmann C, Tabin CJ. Wnt-14 plays a pivotal role in inducing synovial joint formation in the developing appendicular skeleton. Cell. 2001; 104:341-351. [PubMed: 11239392] 
Hemmer KM, McAlister WH, Marsh JL. Cervical spine anomalies in the craniosynostosis syndromes. Cleft Palate J. 1987; 24:328-333. [PubMed: 3479279]

Henriksson HB, Svala E, Skioldebrand E, Lindahl A, Brisby H. Support of concept that migrating progenitor cells from stem cell niches contribute to normal regeneration of the adult mammal intervertebral disc: a descriptive study in the New Zealand white rabbit. Spine (Phila Pa 1976). 2012; 37:722-732. [PubMed: 21897341]

Hill TP, Spater D, Taketo MM, Birchmeier W, Hartmann C. Canonical Wnt/beta-catenin signaling prevents osteoblasts from differentiating into chondrocytes. Dev Cell. 2005; 8:727-738. [PubMed: 15866163]

Holder N. An experimental investigation into the early development of the chick elbow joint. J Embryol Exp Morphol. 1977; 39:115-127. [PubMed: 886251]

Holmes G, Basilico C. Mesodermal expression of Fgfr2S252W is necessary and sufficient to induce craniosynostosis in a mouse model of Apert syndrome. Dev Biol. 2012; 368:283-293. [PubMed: 22664175]

Huang R, Zhi Q, Wilting J, Christ B. The fate of somitocoele cells in avian embryos. Anat Embryol (Berl). 1994; 190:243-250. [PubMed: 7529466]

Hyde G, Boot-Handford RP, Wallis GA. Col2a1 lineage tracing reveals that the meniscus of the knee joint has a complex cellular origin. J Anat. 2008; 213:531-538. [PubMed: 19014360]

Iseki S, Wilkie AO, Heath JK, Ishimaru T, Eto K, Morriss-Kay GM. Fgfr2 and osteopontin domains in the developing skull vault are mutually exclusive and can be altered by locally applied FGF2. Development. 1997; 124:3375-3384. [PubMed: 9310332]

Iseki S, Wilkie AO, Morriss-Kay GM. Fgfr1 and Fgfr2 have distinct differentiation- and proliferationrelated roles in the developing mouse skull vault. Development. 1999; 126:5611-5620. [PubMed: 10572038]

Ishii M, Merrill AE, Chan YS, Gitelman I, Rice DP, Sucov HM, Maxson RE Jr. Msx2 and Twist cooperatively control the development of the neural crest-derived skeletogenic mesenchyme of the murine skull vault. Development. 2003; 130:6131-6142. [PubMed: 14597577]

Ito MM, Kida MY. Morphological and biochemical re-evaluation of the process of cavitation in the rat knee joint: cellular and cell strata alterations in the interzone. J Anat. 2000; 197(Pt 4):659-679. [PubMed: 11197539]

Jiang X, Iseki S, Maxson RE, Sucov HM, Morriss-Kay GM. Tissue origins and interactions in the mammalian skull vault. Dev Biol. 2002; 241:106-116. [PubMed: 11784098]

Kan A, Tabin CJ. c-Jun is required for the specification of joint cell fates. Genes Dev. 2013; 27:514524. [PubMed: 23475960]

Karp SJ, Schipani E, St-Jacques B, Hunzelman J, Kronenberg H, McMahon AP. Indian hedgehog coordinates endochondral bone growth and morphogenesis via parathyroid hormone relatedprotein-dependent and -independent pathways. Development. 2000; 127:543-548. [PubMed: 10631175]

Kavanagh E, Abiri M, Bland YS, Ashhurst DE. Division and death of cells in developing synovial joints and long bones. Cell Biol Int. 2002; 26:679-688. [PubMed: 12175671]

Kavanagh E, Church VL, Osborne AC, Lamb KJ, Archer CW, Francis-West PH, Pitsillides AA. Differential regulation of GDF-5 and FGF-2/4 by immobilisation in ovo exposes distinct roles in joint formation. Dev Dyn. 2006; 235:826-834. [PubMed: 16425226]

Kerr GJ, Veras MA, Kim MK, Seguin CA. Decoding the intervertebral disc: Unravelling the complexities of cell phenotypes and pathways associated with degeneration and mechanotransduction. Semin Cell Dev Biol. 2016

Khonsari RH, Ohazama A, Raouf R, Kawasaki M, Kawasaki K, Porntaveetus T, Ghafoor S, Hammond P, Suttie M, Odri GA, Sandford RN, Wood JN, Sharpe PT. Multiple postnatal craniofacial anomalies are characterized by conditional loss of polycystic kidney disease 2 (Pkd2). Hum Mol Genet. 2013; 22:1873-1885. [PubMed: 23390131]

Kim HJ, Rice DP, Kettunen PJ, Thesleff I. FGF-, BMP- and Shh-mediated signalling pathways in the regulation of cranial suture morphogenesis and calvarial bone development. Development. 1998; 125:1241-1251. [PubMed: 9477322] 
Kobayashi T, Soegiarto DW, Yang Y, Lanske B, Schipani E, McMahon AP, Kronenberg HM. Indian hedgehog stimulates periarticular chondrocyte differentiation to regulate growth plate length independently of PTHrP. J Clin Invest. 2005; 115:1734-1742. [PubMed: 15951842]

Kondo N, Yuasa T, Shimono K, Tung W, Okabe T, Yasuhara R, Pacifici M, Zhang Y, Iwamoto M, Enomoto-Iwamoto M. Intervertebral disc development is regulated by Wnt/beta-catenin signaling. Spine (Phila Pa 1976). 2011; 36:E513-518. [PubMed: 21270710]

Koyama E, Ochiai T, Rountree RB, Kingsley DM, Enomoto-Iwamoto M, Iwamoto M, Pacifici M. Synovial joint formation during mouse limb skeletogenesis: roles of Indian hedgehog signaling. Ann N Y Acad Sci. 2007; 1116:100-112. [PubMed: 18083924]

Koyama E, Shibukawa Y, Nagayama M, Sugito H, Young B, Yuasa T, Okabe T, Ochiai T, Kamiya N, Rountree RB, Kingsley DM, Iwamoto M, Enomoto-Iwamoto M, Pacifici M. A distinct cohort of progenitor cells participates in synovial joint and articular cartilage formation during mouse limb skeletogenesis. Dev Biol. 2008; 316:62-73. [PubMed: 18295755]

Lamande SR, Yuan Y, Gresshoff IL, Rowley L, Belluoccio D, Kaluarachchi K, Little CB, Botzenhart E, Zerres K, Amor DJ, Cole WG, Savarirayan R, McIntyre P, Bateman JF. Mutations in TRPV4 cause an inherited arthropathy of hands and feet. Nat Genet. 2011; 43:1142-1146. [PubMed: 21964574]

Lamb KJ, Lewthwaite JC, Bastow ER, Pitsillides AA. Defining boundaries during joint cavity formation: going out on a limb. Int J Exp Pathol. 2003; 84:55-67. [PubMed: 12801279]

Lana-Elola E, Rice R, Grigoriadis AE, Rice DP. Cell fate specification during calvarial bone and suture development. Dev Biol. 2007; 311:335-346. [PubMed: 17931618]

Lanske B, Karaplis AC, Lee K, Luz A, Vortkamp A, Pirro A, Karperien M, Defize LH, Ho C, Mulligan RC, Abou-Samra AB, Juppner H, Segre GV, Kronenberg HM. PTH/PTHrP receptor in early development and Indian hedgehog-regulated bone growth. Science. 1996; 273:663-666. [PubMed: 8662561]

Lee J, Gardiner DM. Regeneration of limb joints in the axolotl (Ambystoma mexicanum). PLoS One. 2012; 7:e50615. [PubMed: 23185640]

Lee W, Leddy HA, Chen Y, Lee SH, Zelenski NA, McNulty AL, Wu J, Beicker KN, Coles J, Zauscher S, Grandl J, Sachs F, Guilak F, Liedtke WB. Synergy between Piezo1 and Piezo2 channels confers high-strain mechanosensitivity to articular cartilage. Proc Natl Acad Sci U S A. 2014; 111:E51145122. [PubMed: 25385580]

Lenton K, James AW, Manu A, Brugmann SA, Birker D, Nelson ER, Leucht P, Helms JA, Longaker MT. Indian hedgehog positively regulates calvarial ossification and modulates bone morphogenetic protein signaling. Genesis. 2011; 49:784-796. [PubMed: 21557453]

Lewthwaite JC, Bastow ER, Lamb KJ, Blenis J, Wheeler-Jones CP, Pitsillides AA. A specific mechanomodulatory role for p38 MAPK in embryonic joint articular surface cell MEK-ERK pathway regulation. J Biol Chem. 2006; 281:11011-11018. [PubMed: 16464862]

Li X, Leo BM, Beck G, Balian G, Anderson GD. Collagen and proteoglycan abnormalities in the GDF-5-deficient mice and molecular changes when treating disk cells with recombinant growth factor. Spine (Phila Pa 1976). 2004; 29:2229-2234. [PubMed: 15480133]

Liu B, Yu HM, Hsu W. Craniosynostosis caused by Axin2 deficiency is mediated through distinct functions of beta-catenin in proliferation and differentiation. Dev Biol. 2007; 301:298-308. [PubMed: 17113065]

Liu Z, Xu J, Colvin JS, Ornitz DM. Coordination of chondrogenesis and osteogenesis by fibroblast growth factor 18. Genes Dev. 2002; 16:859-869. [PubMed: 11937493]

Maeda Y, Nakamura E, Nguyen MT, Suva LJ, Swain FL, Razzaque MS, Mackem S, Lanske B. Indian Hedgehog produced by postnatal chondrocytes is essential for maintaining a growth plate and trabecular bone. Proc Natl Acad Sci U S A. 2007; 104:6382-6387. [PubMed: 17409191]

Maier JA, Harfe BD. Nuclei pulposi formation from the embryonic notochord occurs normally in GDF-5-deficient mice. Spine (Phila Pa 1976). 2011; 36:E1555-1561. [PubMed: 21278629]

Mak KK, Chen MH, Day TF, Chuang PT, Yang Y. Wnt/beta-catenin signaling interacts differentially with Ihh signaling in controlling endochondral bone and synovial joint formation. Development. 2006; 133:3695-3707. [PubMed: 16936073]

Mao JJ. Mechanobiology of craniofacial sutures. J Dent Res. 2002; 81:810-816. [PubMed: 12454093] 
Markens IS. Embryonic development of the coronal suture in man and rat. Acta Anat (Basel). 1975; 93:257-273. [PubMed: 1211084]

Maruyama T, Mirando AJ, Deng CX, Hsu W. The balance of WNT and FGF signaling influences mesenchymal stem cell fate during skeletal development. Sci Signal. 2010; 3:ra40. [PubMed: 20501936]

Matsunaga S, Nagano S, Onishi T, Morimoto N, Suzuki S, Komiya S. Age-related changes in expression of transforming growth factor-beta and receptors in cells of intervertebral discs. $\mathbf{J}$ Neurosurg. 2003; 98:63-67. [PubMed: 12546390]

McCann MR, Seguin CA. Notochord Cells in Intervertebral Disc Development and Degeneration. J Dev Biol. 2016; 4:1-18. [PubMed: 27252900]

McCann MR, Tamplin OJ, Rossant J, Seguin CA. Tracing notochord-derived cells using a Noto-cre mouse: implications for intervertebral disc development. Dis Model Mech. 2012; 5:73-82. [PubMed: 22028328]

Merrill AE, Bochukova EG, Brugger SM, Ishii M, Pilz DT, Wall SA, Lyons KM, Wilkie AO, Maxson RE Jr. Cell mixing at a neural crest-mesoderm boundary and deficient ephrin-Eph signaling in the pathogenesis of craniosynostosis. Hum Mol Genet. 2006; 15:1319-1328. [PubMed: 16540516]

Mirando AJ, Maruyama T, Fu J, Yu HM, Hsu W. beta-catenin/cyclin D1 mediated development of suture mesenchyme in calvarial morphogenesis. BMC Dev Biol. 2010; 10:116. [PubMed: 21108844]

Mitrovic D. Development of the articular cavity in paralyzed chick embryos and in chick embryo limb buds cultured on chorioallantoic membranes. Acta Anat (Basel). 1982; 113:313-324. [PubMed: 7180379]

Mitrovic DR. Development of the metatarsophalangeal joint of the chick embryo: morphological, ultrastructural and histochemical studies. Am J Anat. 1977; 150:333-347. [PubMed: 920633]

Mittapalli VR, Huang R, Patel K, Christ B, Scaal M. Arthrotome: a specific joint forming compartment in the avian somite. Dev Dyn. 2005; 234:48-53. [PubMed: 16028274]

Mundy C, Yasuda T, Kinumatsu T, Yamaguchi Y, Iwamoto M, Enomoto-Iwamoto M, Koyama E, Pacifici M. Synovial joint formation requires local Ext1 expression and heparan sulfate production in developing mouse embryo limbs and spine. Dev Biol. 2011; 351:70-81. [PubMed: 21185280]

Murakami H, Okawa A, Yoshida H, Nishikawa S, Moriya H, Koseki H. Elbow knee synostosis (Eks): a new mutation on mouse Chromosome 14. Mamm Genome. 2002; 13:341-344. [PubMed: 12140681]

Murray PD, Drachman DB. The role of movement in the development of joints and related structures: the head and neck in the chick embryo. J Embryol Exp Morphol. 1969; 22:349-371. [PubMed: 5360022]

Murtaugh LC, Chyung JH, Lassar AB. Sonic hedgehog promotes somitic chondrogenesis by altering the cellular response to BMP signaling. Genes Dev. 1999; 13:225-237. [PubMed: 9925646]

Nakamichi R, Ito Y, Inui M, Onizuka N, Kayama T, Kataoka K, Suzuki H, Mori M, Inagawa M, Ichinose S, Lotz MK, Sakai D, Masuda K, Ozaki T, Asahara H. Mohawk promotes the maintenance and regeneration of the outer annulus fibrosus of intervertebral discs. Nat Commun. 2016; 7:12503. [PubMed: 27527664]

Nosikova YS, Santerre JP, Grynpas M, Gibson G, Kandel RA. Characterization of the annulus fibrosus-vertebral body interface: identification of new structural features. J Anat. 2012; 221:577589. [PubMed: 22747710]

O'Conor CJ, Leddy HA, Benefield HC, Liedtke WB, Guilak F. TRPV4-mediated mechanotransduction regulates the metabolic response of chondrocytes to dynamic loading. Proc Natl Acad Sci U S A. 2014; 111:1316-1321. [PubMed: 24474754]

Ogawa H, Kozhemyakina E, Hung HH, Grodzinsky AJ, Lassar AB. Mechanical motion promotes expression of Prg4 in articular cartilage via multiple CREB-dependent, fluid flow shear stressinduced signaling pathways. Genes Dev. 2014; 28:127-139. [PubMed: 24449269]

Ohbayashi N, Shibayama M, Kurotaki Y, Imanishi M, Fujimori T, Itoh N, Takada S. FGF18 is required for normal cell proliferation and differentiation during osteogenesis and chondrogenesis. Genes Dev. 2002; 16:870-879. [PubMed: 11937494] 
Osborne AC, Lamb KJ, Lewthwaite JC, Dowthwaite GP, Pitsillides AA. Short-term rigid and flaccid paralyses diminish growth of embryonic chick limbs and abrogate joint cavity formation but differentially preserve pre-cavitated joints. J Musculoskelet Neuronal Interact. 2002; 2:448-456. [PubMed: 15758413]

Pacifici M, Koyama E, Iwamoto M. Mechanisms of synovial joint and articular cartilage formation: recent advances, but many lingering mysteries. Birth Defects Res C Embryo Today. 2005; 75:237-248. [PubMed: 16187328]

Parker WK. A monograph on the structure and development of the shoulder girdle and sternum in the Vertebrata. Ray Society. 1868

Payne SL, Holliday CM, Vickaryous MK. An osteological and histological investigation of cranial joints in geckos. Anat Rec (Hoboken). 2011; 294:399-405. [PubMed: 21254447]

Pelton RW, Dickinson ME, Moses HL, Hogan BL. In situ hybridization analysis of TGF beta 3 RNA expression during mouse development: comparative studies with TGF beta 1 and beta 2 . Development. 1990; 110:609-620. [PubMed: 1723948]

Peters H, Wilm B, Sakai N, Imai K, Maas R, Balling R. Pax1 and Pax9 synergistically regulate vertebral column development. Development. 1999; 126:5399-5408. [PubMed: 10556064]

Pfaff MJ, Xue K, Li L, Horowitz MC, Steinbacher DM, Eswarakumar JV. FGFR2c-mediated ERKMAPK activity regulates coronal suture development. Dev Biol. 2016; 415:242-250. [PubMed: 27034231]

Pitsillides AA, Ashhurst DE. A critical evaluation of specific aspects of joint development. Dev Dyn. 2008; 237:2284-2294. [PubMed: 18729226]

Postacchini F, Bellocci M, Massobrio M. Morphologic changes in annulus fibrosus during aging. An ultrastructural study in rats. Spine (Phila Pa 1976). 1984; 9:596-603. [PubMed: 6495029]

Ray A, Singh PN, Sohaskey ML, Harland RM, Bandyopadhyay A. Precise spatial restriction of BMP signaling is essential for articular cartilage differentiation. Development. 2015; 142:1169-1179. [PubMed: 25758226]

Resende TP, Ferreira M, Teillet MA, Tavares AT, Andrade RP, Palmeirim I. Sonic hedgehog in temporal control of somite formation. Proc Natl Acad Sci U S A. 2010; 107:12907-12912. [PubMed: 20615943]

Rice DP, Aberg T, Chan Y, Tang Z, Kettunen PJ, Pakarinen L, Maxson RE, Thesleff I. Integration of FGF and TWIST in calvarial bone and suture development. Development. 2000; 127:1845-1855. [PubMed: 10751173]

Rice DP, Connor EC, Veltmaat JM, Lana-Elola E, Veistinen L, Tanimoto Y, Bellusci S, Rice R. Gli3Xt-J/Xt-J mice exhibit lambdoid suture craniosynostosis which results from altered osteoprogenitor proliferation and differentiation. Hum Mol Genet. 2010; 19:3457-3467. [PubMed: 20570969]

Rockel JS, Yu C, Whetstone H, Craft AM, Reilly K, Ma H, Tsushima H, Puviindran V, Al-Jazrawe M, Keller GM, Alman BA. Hedgehog inhibits beta-catenin activity in synovial joint development and osteoarthritis. J Clin Invest. 2016; 126:1649-1663. [PubMed: 27018594]

Roddy KA, Prendergast PJ, Murphy P. Mechanical influences on morphogenesis of the knee joint revealed through morphological, molecular and computational analysis of immobilised embryos. PLoS One. 2011; 6:e17526. [PubMed: 21386908]

Rolfe RA, Nowlan NC, Kenny EM, Cormican P, Morris DW, Prendergast PJ, Kelly D, Murphy P. Identification of mechanosensitive genes during skeletal development: alteration of genes associated with cytoskeletal rearrangement and cell signalling pathways. BMC Genomics. 2014; 15:48. [PubMed: 24443808]

Rountree RB, Schoor M, Chen H, Marks ME, Harley V, Mishina Y, Kingsley DM. BMP receptor signaling is required for postnatal maintenance of articular cartilage. PLoS Biol. 2004; 2:e355. [PubMed: 15492776]

Roybal PG, Wu NL, Sun J, Ting MC, Schafer CA, Maxson RE. Inactivation of Msx1 and Msx2 in neural crest reveals an unexpected role in suppressing heterotopic bone formation in the head. Dev Biol. 2010; 343:28-39. [PubMed: 20398647]

Seemann P, Schwappacher R, Kjaer KW, Krakow D, Lehmann K, Dawson K, Stricker S, Pohl J, Ploger F, Staub E, Nickel J, Sebald W, Knaus P, Mundlos S. Activating and deactivating mutations in the 
receptor interaction site of GDF5 cause symphalangism or brachydactyly type A2. J Clin Invest. 2005; 115:2373-2381. [PubMed: 16127465]

Settle SH Jr, Rountree RB, Sinha A, Thacker A, Higgins K, Kingsley DM. Multiple joint and skeletal patterning defects caused by single and double mutations in the mouse Gdf6 and Gdf5 genes. Dev Biol. 2003; 254:116-130. [PubMed: 12606286]

Shen K, Krakora SM, Cunningham M, Singh M, Wang X, Hu FZ, Post JC, Ehrlich GD. Medical treatment of craniosynostosis: recombinant Noggin inhibits coronal suture closure in the rat craniosynostosis model. Orthod Craniofac Res. 2009; 12:254-262. [PubMed: 19627528]

Shwartz Y, Viukov S, Krief S, Zelzer E. Joint Development Involves a Continuous Influx of Gdf5Positive Cells. Cell Rep. 2016; 15:2577-2587. [PubMed: 27292641]

Sivakamasundari V, Lufkin T. Bridging the Gap: Understanding Embryonic Intervertebral Disc Development. Cell Dev Biol. 2012:1.

Soeda T, Deng JM, de Crombrugghe B, Behringer RR, Nakamura T, Akiyama H. Sox9-expressing precursors are the cellular origin of the cruciate ligament of the knee joint and the limb tendons. Genesis. 2010; 48:635-644. [PubMed: 20806356]

Sohn P, Cox M, Chen D, Serra R. Molecular profiling of the developing mouse axial skeleton: a role for Tgfbr2 in the development of the intervertebral disc. BMC Dev Biol. 2010; 10:29. [PubMed: 20214815]

Spater D, Hill TP, Gruber M, Hartmann C. Role of canonical Wnt-signalling in joint formation. Eur Cell Mater. 2006a; 12:71-80. [PubMed: 17115376]

Spater D, Hill TP, O'Sullivan RJ, Gruber M, Conner DA, Hartmann C. Wnt9a signaling is required for joint integrity and regulation of Ihh during chondrogenesis. Development. 2006b; 133:3039_ 3049. [PubMed: 16818445]

St-Jacques B, Hammerschmidt M, McMahon AP. Indian hedgehog signaling regulates proliferation and differentiation of chondrocytes and is essential for bone formation. Genes Dev. 1999; 13:2072-2086. [PubMed: 10465785]

Storm EE, Kingsley DM. Joint patterning defects caused by single and double mutations in members of the bone morphogenetic protein (BMP) family. Development. 1996; 122:3969-3979. [PubMed: 9012517]

Storm EE, Kingsley DM. GDF5 coordinates bone and joint formation during digit development. Dev Biol. 1999; 209:11-27. [PubMed: 10208739]

Strudel G. Morphogenic effect of the neural tube and of the cord on differentiation of the vertebral column and of its muscles in chick embryo. C R Seances Soc Biol Fil. 1955; 149:188-190. [PubMed: 14390873]

Sugimoto Y, Takimoto A, Akiyama H, Kist R, Scherer G, Nakamura T, Hiraki Y, Shukunami C. Scx+/ Sox9+ progenitors contribute to the establishment of the junction between cartilage and tendon/ ligament. Development. 2013; 140:2280-2288. [PubMed: 23615282]

Takahashi Y, Koizumi K, Takagi A, Kitajima S, Inoue T, Koseki H, Saga Y. Mesp2 initiates somite segmentation through the Notch signalling pathway. Nat Genet. 2000; 25:390-396. [PubMed: 10932180]

Takimoto A, Mohri H, Kokubu C, Hiraki Y, Shukunami C. Pax1 acts as a negative regulator of chondrocyte maturation. Exp Cell Res. 2013; 319:3128-3139. [PubMed: 24080012]

Tanimoto Y, Veistinen L, Alakurtti K, Takatalo M, Rice DP. Prevention of premature fusion of calvarial suture in GLI-Kruppel family member 3 (Gli3)-deficient mice by removing one allele of Runtrelated transcription factor 2 (Runx2). J Biol Chem. 2012; 287:21429-21438. [PubMed: 22547067]

Teillet M, Watanabe Y, Jeffs P, Duprez D, Lapointe F, Le Douarin NM. Sonic hedgehog is required for survival of both myogenic and chondrogenic somitic lineages. Development. 1998; 125:2019_ 2030. [PubMed: 9570767]

Teppner I, Becker S, de Angelis MH, Gossler A, Beckers J. Compartmentalised expression of Deltalike 1 in epithelial somites is required for the formation of intervertebral joints. BMC Dev Biol. 2007; 7:68. [PubMed: 17572911] 
Ting MC, Wu NL, Roybal PG, Sun J, Liu L, Yen Y, Maxson RE Jr. EphA4 as an effector of Twist1 in the guidance of osteogenic precursor cells during calvarial bone growth and in craniosynostosis. Development. 2009; 136:855-864. [PubMed: 19201948]

Tsumaki N, Nakase T, Miyaji T, Kakiuchi M, Kimura T, Ochi T, Yoshikawa H. Bone morphogenetic protein signals are required for cartilage formation and differently regulate joint development during skeletogenesis. J Bone Miner Res. 2002; 17:898-906. [PubMed: 12009021]

Twigg SR, Wilkie AO. A Genetic-Pathophysiological Framework for Craniosynostosis. Am J Hum Genet. 2015; 97:359-377. [PubMed: 26340332]

Vortkamp A, Lee K, Lanske B, Segre GV, Kronenberg HM, Tabin CJ. Regulation of rate of cartilage differentiation by Indian hedgehog and PTH-related protein. Science. 1996; 273:613-622. [PubMed: 8662546]

Wallin J, Wilting J, Koseki H, Fritsch R, Christ B, Balling R. The role of Pax-1 in axial skeleton development. Development. 1994; 120:1109-1121. [PubMed: 8026324]

Wang Y, Sun M, Uhlhorn VL, Zhou X, Peter I, Martinez-Abadias N, Hill CA, Percival CJ, Richtsmeier JT, Huso DL, Jabs EW. Activation of p38 MAPK pathway in the skull abnormalities of Apert syndrome Fgfr2(+P253R) mice. BMC Dev Biol. 2010; 10:22. [PubMed: 20175913]

Wang Y, Xiao R, Yang F, Karim BO, Iacovelli AJ, Cai J, Lerner CP, Richtsmeier JT, Leszl JM, Hill CA, Yu K, Ornitz DM, Elisseeff J, Huso DL, Jabs EW. Abnormalities in cartilage and bone development in the Apert syndrome FGFR2(+/S252W) mouse. Development. 2005; 132:35373548. [PubMed: 15975938]

Warren SM, Brunet LJ, Harland RM, Economides AN, Longaker MT. The BMP antagonist noggin regulates cranial suture fusion. Nature. 2003; 422:625-629. [PubMed: 12687003]

Winkler T, Mahoney EJ, Sinner D, Wylie CC, Dahia CL. Wnt signaling activates Shh signaling in early postnatal intervertebral discs, and re-activates Shh signaling in old discs in the mouse. PLoS One. 2014; 9:e98444. [PubMed: 24892825]

Wolfman NM, Hattersley G, Cox K, Celeste AJ, Nelson R, Yamaji N, Dube JL, DiBlasio-Smith E, Nove J, Song JJ, Wozney JM, Rosen V. Ectopic induction of tendon and ligament in rats by growth and differentiation factors 5, 6, and 7, members of the TGF-beta gene family. J Clin Invest. 1997; 100:321-330. [PubMed: 9218508]

Yen HY, Ting MC, Maxson RE. Jagged1 functions downstream of Twist1 in the specification of the coronal suture and the formation of a boundary between osteogenic and non-osteogenic cells. Dev Biol. 2010; 347:258-270. [PubMed: 20727876]

Yin L, Du X, Li C, Xu X, Chen Z, Su N, Zhao L, Qi H, Li F, Xue J, Yang J, Jin M, Deng C, Chen L. A Pro253Arg mutation in fibroblast growth factor receptor 2 (Fgfr2) causes skeleton malformation mimicking human Apert syndrome by affecting both chondrogenesis and osteogenesis. Bone. 2008; 42:631-643. [PubMed: 18242159]

Yoshida T, Vivatbutsiri P, Morriss-Kay G, Saga Y, Iseki S. Cell lineage in mammalian craniofacial mesenchyme. Mech Dev. 2008; 125:797-808. [PubMed: 18617001]

Yu HM, Jerchow B, Sheu TJ, Liu B, Costantini F, Puzas JE, Birchmeier W, Hsu W. The role of Axin2 in calvarial morphogenesis and craniosynostosis. Development. 2005; 132:1995-2005. [PubMed: 15790973]

Yu K, Ornitz DM. Uncoupling fibroblast growth factor receptor 2 ligand binding specificity leads to Apert syndrome-like phenotypes. Proc Natl Acad Sci U S A. 2001; 98:3641-3643. [PubMed: 11274381]

Yu K, Xu J, Liu Z, Sosic D, Shao J, Olson EN, Towler DA, Ornitz DM. Conditional inactivation of FGF receptor 2 reveals an essential role for FGF signaling in the regulation of osteoblast function and bone growth. Development. 2003; 130:3063-3074. [PubMed: 12756187]

Zhang N, Gridley T. Defects in somite formation in lunatic fringe-deficient mice. Nature. 1998; 394:374-377. [PubMed: 9690472]

Zhao H, Feng J, Ho TV, Grimes W, Urata M, Chai Y. The suture provides a niche for mesenchymal stem cells of craniofacial bones. Nat Cell Biol. 2015; 17:386-396. [PubMed: 25799059]

Zhou YX, Xu X, Chen L, Li C, Brodie SG, Deng CX. A Pro250Arg substitution in mouse Fgfr1 causes increased expression of Cbfa1 and premature fusion of calvarial sutures. Hum Mol Genet. 2000; 9:2001-2008. [PubMed: 10942429] 
Zieba J, Forlenza KN, Khatra JS, Sarukhanov A, Duran I, Rigueur D, Lyons KM, Cohn DH, Merrill AE, Krakow D. TGFbeta and BMP Dependent Cell Fate Changes Due to Loss of Filamin B Produces Disc Degeneration and Progressive Vertebral Fusions. PLoS Genet. 2016; 12:e1005936. [PubMed: 27019229]

Zou H, Wieser R, Massague J, Niswander L. Distinct roles of type I bone morphogenetic protein receptors in the formation and differentiation of cartilage. Genes Dev. 1997; 11:2191-2203. [PubMed: 9303535] 


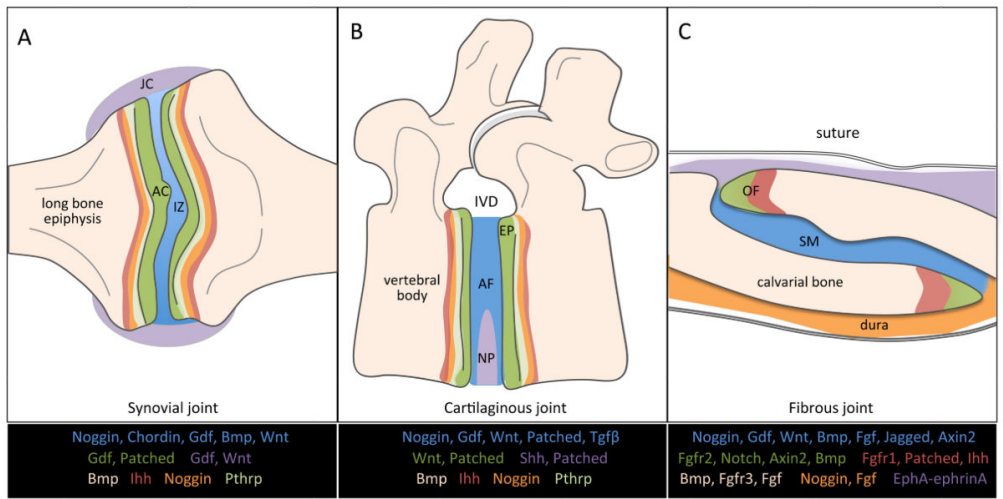

Figure 1. Spatial expression patterns of the principal signaling pathways in joint development The expression domains of critical signaling pathway components are regionally restricted during development of the (A) synovial, (B) cartilaginous, and (C) fibrous joints. Articular cartilage (AC); interzone (IZ); joint capsule (JC); intervertebral disc (IVD); endplate (EP); annulus fibrosus (AF); nucleus pulposus (NP); osteogenic front (OF); and mid-suture mesenchyme (SM). 
A

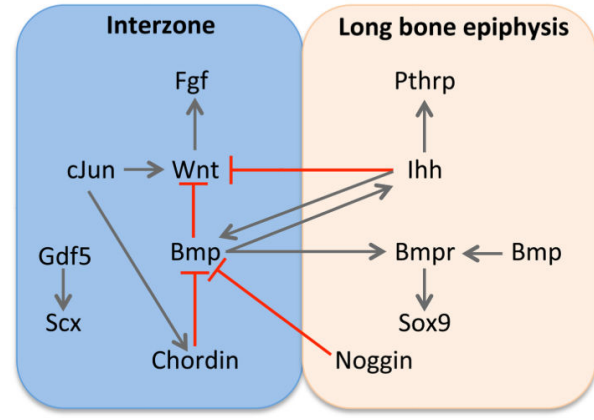

B

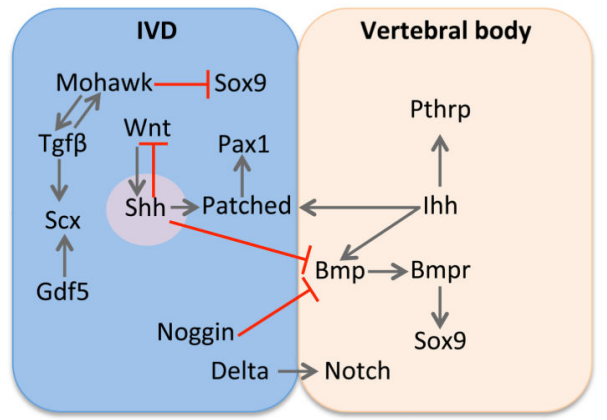

C

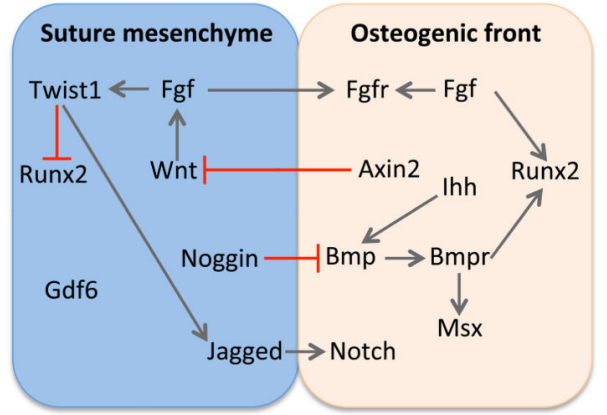

Figure 2. Signaling networks in joint development have unifying features There is overlap in the principal signaling pathways and their regulatory interactions between (A) synovial joints, (B) cartilaginous joints, and (C) fibrous joints. 